\title{
ENSINO DE EMPREENDEDORISMO: UTILIZAÇÃO DO BUSINESS MODEL GENERATION
}

\author{
Patricia Viveiros de Castro Krakauer \\ Doutora em Administração pela Universidade de São Paulo - USP \\ Professora Convidada da Universidade de São Paulo - USP \\ pkrakauer@terra.com.br (Brasil)

\section{Maria Cecilia Galante Porto} \\ Doutoranda em Administração da Faculdade de Economia, Administração e Contabilidade - FEAC/USP \\ mceciliagalante@uol.com.br (Brasil)
}

\section{Claudio Soares de Moura e Oliveira}

Mestrando em Administração da Faculdade de Economia, Administração e Contabilidade - FEAC/USP

Claudio.Moura@br.mcd.com (Brasil)

\section{Martinho Isnard Ribeiro de Almeida}

Doutor em Administração pela Universidade de São Paulo - USP

Professor da Universidade de São Paulo - USP

martinho@usp.br (Brasil)

\section{RESUMO}

O presente estudo procurou descrever como utilizar o Business Model Generation em aulas de empreendedorismo, objetivando apresentar a metodologia utilizada para aplicar o modelo em sala de aula e a percepção dos alunos sobre o uso de um modelo prático durante o aprendizado. A fundamentação teórica realizada versou sobre o modelo em si e seus antecedentes, sendo na sequência descrita a aplicação do Business Model Generation na disciplina de empreendedorismo na Faculdade de Economia e Administração da Universidade de São Paulo. Foi realizada uma pesquisa qualitativa com os grupos de alunos, no total de quatorze, verificando-se que os mesmos aprovaram a iniciativa, sendo ressaltados pontos fortes e fracos da utilização do modelo em sala de aula. Além disso, apresentou-se a percepção dos docentes sobre a utilização do modelo. Trata-se de um estudo descritivo, qualitativo, considerado como um caso de ensino. Poderá contribuir com docentes de graduação na decisão de utilizar o modelo em sala de aula, além de promover o início de pesquisas de temas relacionados ao modelo, uma vez que ainda são poucos os esforços acadêmicos realizados nesse sentido.

Palavras-Chave: Business Model Generation; Empreendedorismo; Caso de ensino. 


\section{INTRODUÇÃO}

Modelo de negócios é um tema já consagrado na literatura e de fundamental importância para empresas de todos os portes, em especial para as nascentes, que através de tal metodologia podem entender quem é o seu cliente, qual a sua proposição de valor e como transformará isso em receita. Os modelos de negócios possibilitam que o empreendedor pense efetivamente sobre o seu negócio.

Uma abordagem que despontou no mundo de negócios recentemente é o Business Model Generation (BMG), desenvolvido por Osterwalder e Pigneur (2010). Segundo os autores, várias empresas já utilizaram o modelo, como Skype, Procter \& Gamble e Glaxo. Contudo, pouco ainda se tem publicado na academia sobre o tema: ao se realizar um levantamento em Maio/2012 nas bases de dados Web of Science e Ebsco, verificou-se que apenas um trabalho, o de Oliveira e Ferreira (2011), direcionava seus esforços para a análise do BMG, o que pode representar uma lacuna no conhecimento de sua aplicabilidade.

Por ser um modelo desenvolvido de forma dinâmica e com a proposta de facilidade de uso, além de já ter sido testado em vários países e por diversas organizações (OSTERWALDER; PIGNEUR, 2010), vislumbrou-se a possibilidade de utilizar tal modelo para a aprendizagem de alunos de empreendedorismo, buscando com essa metodologia ensinar aos alunos praticando.

Tal perspectiva atenderia a proeminente discussão de se aproximar o aprendizado da realidade que o aluno irá encontrar no mundo corporativo ou ao abrir seu negócio. Autores como Hsu (2011), Korthagen (2001) e Warhurst (2011) possuem pesquisas nesse sentido. Vale destacar o artigo de Hsu (2011) que analisa um método alternativo de ensino que visa a maior participação do aluno e o desenvolvimento de habilidades práticas, concluindo que o uso de tal método possivelmente aumenta o envolvimento do aluno com o aprendizado, além de proporcionar vários benefícios.

Com relação ao empreendedorismo, é interessante comentar sobre a teoria de Sara Sarasvathy, renomada professora de empreendedorismo. Sarasvathy (2001) acredita que as escolas de administração ensinam por meio de uma lógica preditiva, causal e que o empreendedorismo muitas vezes não se adequa a esse modelo. Argumenta que o empreendedorismo pode ser lecionado utilizando um raciocínio denominado pela autora como effectuation, no qual as decisões são circunstanciais, práticas, e considerando o que se tem de disponibilidade no momento em termos de capacidade e networking.

Revista de Administração e Inovação, São Paulo, v. 12, n.1, p.07-23, jan./mar. 2015. 
Diante desse contexto, o presente estudo tem uma proposta descritiva e busca responder a seguinte questão: Como utilizar o Business Model Generation em aulas de empreendedorismo? Como objetivo geral procurou-se descrever a utilização do BMG em uma disciplina de empreendedorismo e de forma especifica aprofundou-se em dois aspectos: (1) a metodologia utilizada para aplicar o modelo em sala de aula e (2) a percepção dos alunos e dos docentes sobre o uso de um modelo prático durante o aprendizado.

Justifica-se a escolha do Business Model Generation em função da sugestão de Oliveira e Ferreira (2011) de que acreditam ser o BMG de grande interesse e utilidade para estudantes que têm a seu dispor um modelo poderoso, simples e já testado empiricamente.

\section{REVISÃO DA LITERATURA}

Neste capítulo será apresentado o modelo BMG de forma que seja o alicerce para a aplicação em campo que será descrita no capítulo 4, na sequência do presente estudo, bem como antecedentes que fundamentaram o desenvolvimento do modelo.

\subsection{Antecedentes}

Apesar do Business Model Generation ser tema recente na literatura, trabalhos anteriores já contemplavam o tema modelo de negócios, conforme constatado por Oliveira e Ferreira (2011). Segundo os autores, analisando a pesquisa de Osterwalder et al. (2005), desde 1957 pode se observar esforços acadêmicos nesse sentido. Mais recentemente citam trabalhos que podem ser considerados como percursores do BMG, como os de Osterwalder (2004), Osterwalder et al. (2005) e Fritscher e Pigneur (2010).

Osterwalder (2004), motivado pela popularidade do termo business model, apresenta em sua tese de doutorado uma abordagem ontológica do assunto com a realização de um estudo de caso do Montreux Jazz Festival. Preocupado com o espírito empreendedor, além de revisar a literatura, o autor discute aspectos relacionados à aplicabilidade e considera o estudo como uma busca de novas maneiras de criar valor e desenvolver novos negócios. 
Um ano depois, Osterwalder et al. (2005) discutem os conceitos de modelos de negócios, sua aplicabilidade e a relação com sistemas de informação. Acreditam que o assunto ainda era discutido na literatura de forma superficial e discutem várias definições de modelo de negócios, chegando à conclusão que a melhor forma de defini-lo seria como uma ferramenta conceitual que tem como principal objetivo expressar a lógica do negócio de uma determinada empresa. Nesse trabalho também pode ser observada uma pesquisa bibliométrica sobre o tema, bem como a evolução acadêmica do termo business model, a sua contextualização e terminologias.

Em um trabalho mais recente, Fritscher e Pigneur (2010) apresentam um modelo com características semelhantes ao proposto por Osterwalder e Pigneur (2010), objeto do presente estudo. Partindo de modelos da engenharia e da gestão de processos, a proposta de Fritscher e Pigneur (2010) foi desenvolver um modelo voltado a um contexto de negócios, que atendesse às necessidades estratégicas, considerando como o principal desafio o não comprometimento da criatividade. Desenvolvido a partir de uma profunda revisão da literatura, o modelo que denominaram de business model ontology continha nove blocos, sendo a sua peculiaridade a capacidade de descrever a lógica do negócio em uma única página.

Vale também citar pesquisas de outros autores, como Magretta (2002) e Timmers (1998) que constituíram importante base teórica sobre o tema e foram citados em vários dos trabalhos analisados acima considerados por Oliveira e Ferreira (2011) como antecessores ao modelo de Osterwalder e Pigneur (2010).

\subsection{Business Model Generation (BMG)}

Para Osterwalder e Pigneur (2010, p. 14) "o modelo de negócios deve descrever de forma racional como uma organização cria, entrega e captura valor", sendo que o modelo, desenvolvido pelos autores acima citados em co-criação com 470 profissionais de 45 países, pode ser facilmente compartilhado e manipulado pelas pessoas com o objetivo de desenvolver alternativas estratégicas.

Elaborado em nove blocos que constituem o que os autores (Ibid.) denominam de canvas, um tipo de tela se traduzido para o português, o modelo foi desenvolvido de forma análoga ao cérebro humano, ou seja, o lado esquerdo do canvas volta-se a eficiência - sendo o lado esquerdo do cérebro voltado à lógica - enquanto o lado direito preocupa-se com os valores - a emoção, ao se considerar o cérebro humano. Na Figura 1 pode-se observar o canvas.

Revista de Administração e Inovação, São Paulo, v. 12, n.1, p.07-23, jan./mar. 2015. 


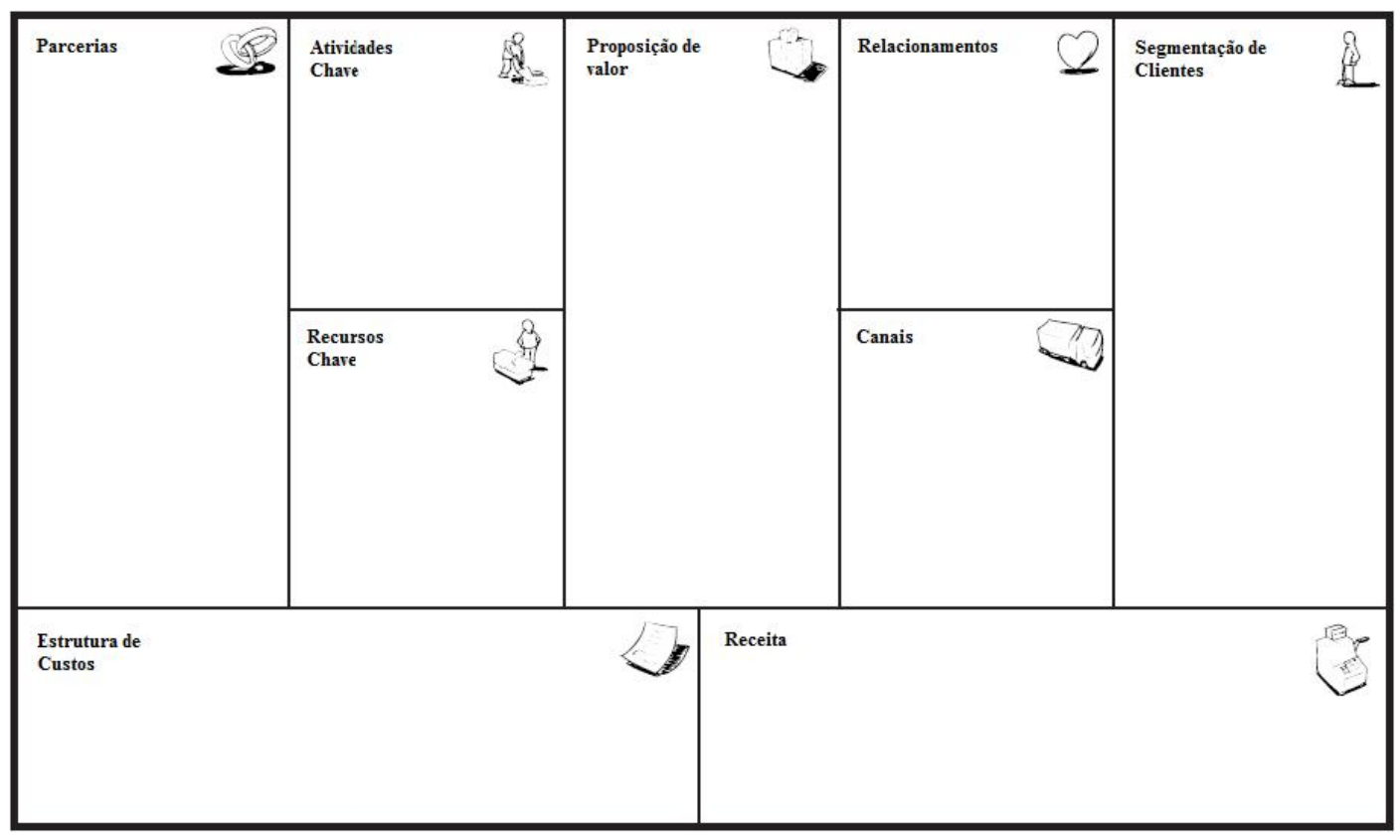

Figura 1: Canvas do BMG

Fonte: Osterwalder e Pigneur (2010).

O primeiro bloco descrito pelos autores é a segmentação de clientes que, segundo os autores é a parte que definirá quais grupos de clientes ou organizações a empresa poderá atender, realizando uma decisão consciente nesse sentido. Osterwalder e Pigneur (2010) consideram que os grupos de consumidores constituem segmentos diferentes se apresentam diferenças relacionadas a: oferta, canais de distribuição, tipo de relacionamentos, lucratividade e interesse, além da disposição relacionada ao pagamento.

O bloco seguinte refere-se à proposição de valor, quando são descritos os produtos e serviços que geram valor para o segmento selecionado no bloco anterior. Algumas proposições podem ser inovativas enquanto outras podem adicionar características e atributos que irão valorar a entrega. Os autores citam vários exemplos, entre eles, redução de custos, design, acessibilidade e usabilidade.

No terceiro bloco devem ser pensadas questões relacionadas aos canais, objetivando "encontrar o correto mix de canais que irá atender como os consumidores querem ser alcançados" (OSTERWALDER; PIGNEUR, 2010, p. 27). Além disso, nesse bloco decide-se pela forma de integração dos canais. O relacionamento faz parte do quarto bloco onde são analisadas questões como: relacionamento pretende-se oferecer, quais são esperados pelo meu cliente e custos correlacionados. 
No bloco seguinte são discutidas questões relativas à receita, quando deve ser analisado por quais valores o cliente está disposto a pagar. Os autores (Ibid.) apresentam diversas formas de se gerar receita, entre elas: taxas de utilização, vendas, taxas de inscrição, licenças e leasing.

O sexto bloco é dedicado aos recursos chaves, enquanto o sétimo às atividades chave. No caso dos recursos, deve-se descrever quais são os recursos que utilizará para criar, distribuir e acumular valor e podem ser segundo os autores (Ibid.): físicos, intelectuais, humanos e financeiros. No caso das atividades chaves, referem-se ao tipo de atividades e processos você precisa cumprir para atingir a meta de gerar valor para seu cliente.

O próximo bloco preocupa-se com as parcerias, descrevendo a cadeia de fornecedores e parceiros. E no último bloco, a estrutura de custo do negócio em análise. Nesse bloco devem ser considerados os custos mais importantes envolvidos na operação

Além da descrição do canvas, que compõe a estrutura do modelo, os autores também apresentam exemplos, metodologias para a aplicação e desenvolvimento de ideias, como brainstormig, contador de estórias, desing thinking, entre outros. Também são apresentados aspectos da análise do ambiente para, segundo os autores (OSTERWALDER; PIGNEUR, 2010, p. 199) permita que o leitor "examine estrategicamente o ambiente no qual o seu modelo de negócios funciona." Discutem questões relacionadas ao ambiente empresarial, a estratégia do oceano azul desenvolvida por Kim e Mauborgne (2005) e a análise SWOT, sob a perspectiva de construção e evolução do BMG.

Um dos últimos capítulos do livro de Osterwalder e Pigneur (2010) refere-se à aplicação do modelo, proposta em um processo de cinco fases, sendo parte desse processo o foco do presente estudo. No Quadro 1 podem ser observadas todas as fases propostas para a elaboração do modelo.

Quadro 1: As cinco fases do BMG

\begin{tabular}{|c|c|c|c|}
\hline Fases & Objetivo & Foco & Descrição \\
\hline Mobilização & $\begin{array}{l}\text { Preparação para } \\
\text { um projeto de } \\
\text { sucesso }\end{array}$ & $\begin{array}{c}\text { Preparando } \\
\text { o terreno }\end{array}$ & $\begin{array}{l}\text { Reunir todos os elementos } \\
\text { necessários, criar a } \\
\text { consciência da necessidade } \\
\text { de um novo negócio, } \\
\text { descrever a motivação por } \\
\text { trás do projeto, estabelecer } \\
\text { uma linguagem comum. }\end{array}$ \\
\hline Entendimento & $\begin{array}{c}\text { Pesquisar e analisar } \\
\text { os elementos } \\
\text { necessários para o } \\
\text { esforço }\end{array}$ & Imersão & $\begin{array}{c}\text { Adquirir conhecimento } \\
\text { relevante sobre: } \\
\text { consumidores, tecnologia e } \\
\text { ambiente através da coleta } \\
\text { de dados, entrevistas com } \\
\text { especialistas e } \\
\text { consumidores, identificando }\end{array}$ \\
\hline
\end{tabular}

Revista de Administração e Inovação, São Paulo, v. 12, n.1, p.07-23, jan./mar. 2015. 


\begin{tabular}{|c|c|c|c|}
\hline & & & necessidades e problemas. \\
\hline Design & $\begin{array}{c}\text { Gerar e testar } \\
\text { opções viáveis de } \\
\text { modelos de } \\
\text { negócios, } \\
\text { selecionando a } \\
\text { melhor }\end{array}$ & Investigação & $\begin{array}{l}\text { Transformar a informação e } \\
\text { ideias em protótipos que } \\
\text { possam ser explorados e } \\
\text { testados. }\end{array}$ \\
\hline Implementação & $\begin{array}{c}\text { Implementar o } \\
\text { protótipo }\end{array}$ & Execução & $\begin{array}{c}\text { Implementar a opção } \\
\text { selecionada }\end{array}$ \\
\hline Gerenciamento & $\begin{array}{c}\text { Adaptar e } \\
\text { modificar o } \\
\text { modelo de acordo } \\
\text { com a reação do } \\
\text { mercado }\end{array}$ & Evolução & $\begin{array}{c}\text { Configurar a estrutura } \\
\text { gerencial para } \\
\text { continuamente monitorar, } \\
\text { evoluir e adaptar ou } \\
\text { transformar }\end{array}$ \\
\hline
\end{tabular}

Fonte: adaptado de Osterwalder e Pigneur (2010).

Conforme pode ser observado no Quadro 1, na primeira fase as principais atividades concentram-se em elaborar os objetivos do projeto, discutir ideias e reunir a equipe de trabalho. $\mathrm{Na}$ segunda fase, os autores ressaltam a importância do bom entendimento do ambiente e recomendam o uso de modelos estratégicos para análise do ambiente, alguns já consolidados na literatura como a análise SWOT. Na fase seguinte, denominada como desenho do modelo, a equipe deve abandonar o status quo possibilitando a idealização dos possíveis modelos de negócios, co-criando em conjunto com todos da organização. A fase de implementação e gerenciamento dizem respeito à execução do que foi gerando, sendo que essas fases não são o foco do BMG, segundo o que acreditam Osterwalder e Pigneur (2010).

\section{METODOLOGIA}

De acordo com a problemática do presente estudo e dos objetivos traçados, trata-se de um estudo descritivo, com abordagem qualitativa, que buscou apresentar a utilização do BMG em sala de aula, tratando-se, portanto, de um caso de ensino.

Nono e Mizukami (2002, p. 72) comentam que desde a década de 80 casos de ensino são considerados como importantes instrumentos para a formação de professores e na investigação de processos didáticos e definem caso de ensino como sendo um trabalho de cunho "descritivo de situações reais ou baseadas na realidade", tratando-se de uma "representação multidimensional do contexto". Além disso, comentam que casos de ensino possibilitam o estudo de várias temáticas e contextos possíveis em sala de aula. 
A aplicação do modelo ocorreu na Faculdade de Economia, Administração e Contabilidade da Universidade de São Paulo, na disciplina de empreendedorismo, tendo sido esta escolhida pela conveniência dos pesquisadores e pelo maior interesse dos alunos que frequentam tal disciplina em abrir um novo negócio. A disciplina é optativa, oferecida no primeiro semestre de 2012, no curso noturno, com 61 alunos que cursavam em sua maioria o último período da faculdade de administração. Participaram especialmente desse trabalho o professor da disciplina e quatro professores monitores.

Para a realização da pesquisa empírica, pode-se dividir o método em três fases subsequentes: (1) Observação participante dos docentes em sala de aula objetivando descrever a aplicação, (2) entrevistas com os grupos de alunos com a finalidade de perceber a percepção dos mesmos sobre a aplicação do modelo e (3) coleta dos testemunhos dos docentes da disciplina.

$\mathrm{Na}$ etapa 1 foram realizados pelos docentes registros precisos de todos os passos realizados em sala de aula, considerando alguns pontos em especial: (1) exposição dos professores, (2) atividades dos alunos, (3) resultados esperados e (4) observações dos decentes.

$\mathrm{Na}$ etapa 2 foram distribuídos questionários aos grupos de alunos que participaram da elaboração do modelo de negócios utilizando o BMG, no total de 14 grupos, sendo que para tal entrevista foi desenvolvido um questionário sobre a atividade onde os principais pontos versavam sobre: (1) percepção sobre o uso do modelo, (2) percepção sobre a utilidade futura de tal aprendizado e (3) pontos fortes e fracos da utilização do modelo como parte do aprendizado.

Vale ressaltar que os grupos foram formados por estudantes da Faculdade de Administração, a maioria do último período da graduação, regularmente matriculados na disciplina de empreendedorismo. Cada grupo recebeu apenas um questionário e deveriam discutir as questões, apresentando no final uma devolutiva. Optou-se por tal metodologia de forma a garantir uma maior reflexão dos alunos sobre as questões, conforme explicitado por Flick (2009).

$\mathrm{Na}$ etapa 3 foram entrevistados dois docentes da disciplina, de forma a avaliar a percepção sobre a utilização dos alunos através de um olhar diferenciado, propondo sugestão de aprimoramento para o futuro.

Os dados foram analisados de forma qualitativa, considerando-se uma leitura cética das devolutivas, sendo os mesmos tabulados e comparados, de forma a possibilitar a discussão dos resultados que pode ser verificada no capítulo seguinte. Após a tabulação, os resultados foram discutidos entre os docentes, possibilitando uma percepção geral da aplicação. 


\section{RESULTADOS}

Apresentam-se a seguir a descrição da aplicação do modelo Business Model Generation em sala de aula e a percepção dos alunos, graduandos em administração, sobre a utilização do BMG.

\subsection{Descrição da aplicação}

Antes do início das aulas foi realizada uma reunião de planejamento, de forma a definir como seria a utilização do modelo BMG em sala de aula. Desse encontro entre o docente e os monitores da disciplina, foi decidido que: (1) Na primeira aula haveria uma explicação geral da metodologia, (2) das quinze aulas do curso, cinco seriam destinadas ao desenvolvimento do modelo, (3) em cada uma das cinco aulas o grupo de discentes deveria construir um ou mais blocos do BMG, sendo que haveria uma explicação prévia de cada etapa e (4) as outras dez aulas seriam prévias à utilização do modelo e seriam utilizadas para explanação teórica de empreendedorismo e palestras de convidados, com a intenção de formar uma base conceitual.

$\mathrm{Na}$ aula inaugural da disciplina foi realizada uma explicação de como seria o curso e a utilização do modelo BMG nas cinco aulas finais do curso. Na aula denominada no presente estudo como sessão 1, mas referente a décima aula do curso, que aconteceu no dia 15/Maio/2012, foram retomadas as questões referentes ao BMG, explanadas na aula inicial do curso, bem como ministrada uma aula de 40 minutos sobre análise do ambiente, reforçando a atividade que os alunos fariam de entendimento do negócio. A partir da ideia de um aluno em empreender em um novo negócio, os demais alunos escolheram seus grupos, totalizando quatorze grupos com diferentes propostas de negócios. Pode-se considerar, portanto, que a sessão 1 referiu-se as etapas denominada por Osterwalder e Pigneur (2010) como mobilização e entendimento (Quadro 1), com o objetivo de preparar a elaboração do BMG.

Nessa seção foram distribuídos canvas aos alunos, sendo que esse painel iria ser utilizado pelo grupo até o final do projeto, além de ser disponibilizado aos alunos post-it para a execução das tarefas. Os professores monitores da disciplina foram designados como facilitadores dos grupos, de forma a conduzir de modo mais próximo a elaboração do BMG dos grupos.

Na sessão 2, em 22/05/2012, foi realizada uma apresentação sobre Segmento de Clientes e Relacionamento, sendo estes os dois blocos que deveriam ser completados no modelo pelos grupos. Notou-se que os grupos conseguiram direcionar suas empresas para o atendimento de um único segmento específico de mercado. Além disso, propuseram diversas ideias de relacionamento com este

Revista de Administração e Inovação, São Paulo, v. 12, n.1, p.07-23, jan./mar. 2015. 
segmento, sobretudo mediante o uso de tecnologias em ambientes online. Um ponto destacado pelos grupos, e abordado no conteúdo da aula, foi a questão da co-criação, ou seja, a preocupação de se criar produtos e serviços de acordo com as ideias, sugestões, desejos e expectativas do segmento de clientes.

No dia 29/05/2012 aconteceu a sessão 3, sendo apresentado aos alunos conceitos sobre proposta de valor, destacando-se os onze elementos que contribuem para a criação de uma proposta de valor, conforme conteúdo abordado no livro de Osterwalder e Pigneur (2010). Abordou-se também a importância do tema inovação como sendo uma das principais fontes de vantagem competitiva de uma empresa, além da demonstração da Análise SWOT para proposta de valor (OSTERWALDER; PIGNEUR, 2010, p.216).

A atividade proposta foi a de que os grupos refletissem sobre os onze elementos e destacassem aqueles que faziam mais sentido para o negócio deles. Deveriam definir o conteúdo de cada elemento para a criação da proposta de valor para sua empresa, bem como responder às 4 questões-guia propostas por Osterwalder e Pigneur (2010, p.23). Foi solicitado que resumissem numa única frase/slogan os principais elementos, revelando com clareza a proposta de valor para o segmento a ser atendido.

Na sessão 4, dia 05/06/2012, foram retomados os conceitos de recursos tangíveis e intangíveis, bem como caracterizou-se os principais recursos ou capacidades da empresa: financeiro, físico, humano e organizacional. A atividade proposta para os grupos foi a de que refletissem sobre os conceitos apresentados e, sobretudo, sobre o conceito VRIO de Barney (1991)., isto é, recursos valiosos, raros, imitáveis e aplicados à organização, respondendo às perguntas propostas por Osterwalder e Pigneur (2010). Interessante ressaltar que um elemento destacado por grande parte dos grupos foi a preocupação com os recursos humanos, sobretudo relacionado ao atendimento no ponto de venda e ao relacionamento pós-venda, sendo que vários grupos comentaram ser um recurso extremamente valioso nas empresas atualmente.

A sessão 5, ocorrida em 12/06/2012, foi a última sessão utilizada para a elaboração do BMG pelos grupos, sendo destacados os seguintes conceitos: (1) parcerias, destacando conceitos sobre alianças estratégicas, joint venture e relação comprador-fornecedor; (2) canais, como a forma pela qual a empresa se comunica com os clientes para entregar sua proposta de valor; (3) receitas, sendo ressaltados dois diferentes tipos de Receitas: transação de renda ou renda recorrente. Comentou-se sobre as formas de geração de receitas, além de mecanismos de precificação e (4) custos, destacandose o conceito de estrutura de custos e os tipos de estruturas de custos. A atividade proposta foi a de que os grupos refletissem sobre os conceitos apresentados, aplicando-os à realidade da empresa em formação.

Revista de Administração e Inovação, São Paulo, v. 12, n.1, p.07-23, jan./mar. 2015. 
Nessa última sessão foi distribuído o questionário de avaliação aos grupos de discentes, sendo que tais resultados serão discutidos no item 4.2.

O Quadro 2 apresenta um resumo de todas as aulas utilizadas para aplicar o BMG, bem como a relação com as fases propostas por Osterwalder e Pigneur (2010) descritas no Quadro 1, apresentado no item 2.2.

\begin{tabular}{|c|c|c|c|}
\multicolumn{4}{|c|}{ Quadro 2: Resumo das aulas destinadas à elaboração do BMG } \\
\hline Sessão & Data & Exposição dos docentes & Fase do BMG \\
\hline 1 & $15 / 05 / 2012$ & Análise do ambiente & $\begin{array}{c}\text { Mobilização/ } \\
\text { Entendimento }\end{array}$ \\
\hline 2 & $22 / 05 / 2012$ & $\begin{array}{c}\text { Segmento de Clientes e } \\
\text { Relacionamento }\end{array}$ & Design \\
\hline 3 & $29 / 05 / 2012$ & Proposta de valor & Design \\
\hline 4 & $05 / 06 / 2012$ & Recursos & Design \\
\hline 5 & $12 / 06 / 2012$ & $\begin{array}{c}\text { Parcerias, Canais, Receitas e } \\
\text { Custos }\end{array}$ \\
\hline
\end{tabular}

Ressalta-se que as fases de implementação e gerenciamento apresentadas no Quadro 1 não foram possíveis em sala de aula em função do tempo despendido para as atividades e da dinâmica de utilização do modelo, o que vai ao encontro do preconizado por Osterwalder e Pigneur (2010) que consideram que ambas as etapas são posteriores à elaboração do modelo, pois dizem respeito à execução do projeto.

\subsection{Percepção dos alunos e dos docentes}

A percepção geral dos grupos sobre a utilização do BMG durante a aula de empreendedorismo foi a de uma experiência interessante e relevante para o aprendizado, auxiliando os alunos a ter uma visão sistêmica e integrada de um negócio, com um olhar mais próximo da realidade empresarial. O Grupo 13, inclusive, comentou que tal metodologia "fez o aluno pensar", sendo "ótimo realizar uma atividade prática em aula". A isto o grupo 10 acrescentou: "Finalmente aprendemos algo prático em aula". 
Com relação aos pontos fortes e fracos citados pode-se verificar que vários grupos de alunos aprovaram a iniciativa de se trabalhar em grupo e poder desenvolver uma ideia em conjunto com outros alunos, destacando a importância de se concluir um projeto prático ao final da disciplina. Alguns grupos focaram a sua resposta na metodologia e outros no modelo em si, como pode ser verificado no Quadro 3.

\section{Quadro 3: Pontos fortes e fracos citados pelos grupos de alunos}

\begin{tabular}{|c|c|c|}
\hline Grupos & Pontos Fortes & Pontos Fracos \\
\hline 1 & $\begin{array}{l}\text { Discutir ideias em grupo. } \\
\text { Ouvir ideias dos outros. }\end{array}$ & $\begin{array}{c}\text { Pouco tempo. } \\
\text { Ambiente difícil para o trabalho em } \\
\text { grupo. }\end{array}$ \\
\hline 2 & Facilitou a organização do pensamento. & Pouco aprofundamento. \\
\hline 3 & $\begin{array}{l}\text { Aprendizado sólido, pois o modelo não é } \\
\text { estático. }\end{array}$ & Pequeno enfoque na parte operacional. \\
\hline 4 & Não comentou. & $\begin{array}{l}\text { O modelo não é adequado para } \\
\text { empresas sociais. }\end{array}$ \\
\hline 5 & $\begin{array}{l}\text { Permitiu o desenvolvimento de uma } \\
\text { visão macro. }\end{array}$ & $\begin{array}{c}\text { Muitas decisões do grupo foram } \\
\text { baseadas no feeling, pois era difícil a } \\
\text { pesquisa durante as aulas. }\end{array}$ \\
\hline 6 & $\begin{array}{c}\text { Facilidade de aprendizado. } \\
\text { Proporcionou o resgate de conceitos. }\end{array}$ & Não comentou \\
\hline 7 & $\begin{array}{l}\text { Interessante estimular o brainstorming. } \\
\text { Aproximou o relacionamento entre aluno } \\
\text { e professores/monitores }\end{array}$ & $\begin{array}{l}\text { Deveria começar antes no curso, pois } \\
\text { no momento em que os alunos estão é } \\
\text { difícil compartilhar tarefas em casa. }\end{array}$ \\
\hline 8 & $\begin{array}{l}\text { Utilizado de maneira participativa. } \\
\text { Facilitou ser dividido em etapas. }\end{array}$ & $\begin{array}{l}\text { Aulas expositivas trazem conceitos } \\
\text { básicos. } \\
\text { Os exemplos são de grandes empresas. }\end{array}$ \\
\hline 9 & Flexibilidade e simplicidade. & $\begin{array}{l}\text { Faltou bibliografia adicional. } \\
\text { Faltou comparação com outros } \\
\text { modelos. }\end{array}$ \\
\hline 10 & $\begin{array}{c}\text { Adaptável. } \\
\text { Facilitou o contato com os professores. }\end{array}$ & $\begin{array}{l}\text { Demorado, o término da aula às vezes } \\
\text { interrompe a ideia. }\end{array}$ \\
\hline 11 & $\begin{array}{l}\text { Facilidade de manusear e de organização } \\
\text { das ideias. }\end{array}$ & $\begin{array}{l}\text { Nem tudo pode ser utilizado em uma } \\
\text { grande organização. }\end{array}$ \\
\hline 12 & $\begin{array}{l}\text { Trabalho em grupo e a consolidação de } \\
\text { um projeto durante a disciplina. }\end{array}$ & $\begin{array}{l}\text { Pequena participação de alguns alunos. } \\
\text { Dificuldade de obter informações na } \\
\text { aula }\end{array}$ \\
\hline 13 & $\begin{array}{c}\text { Visualização do projeto inteiro ao final } \\
\text { da disciplina. } \\
\text { Aprendizado por brainstorming. } \\
\text { Discussão em grupo. } \\
\end{array}$ & Tempo limitado. \\
\hline 14 & Mostra os principais pontos do negócio. & $\begin{array}{c}\text { Não tem analise financeira e de } \\
\text { viabilidade. }\end{array}$ \\
\hline
\end{tabular}

Verifica-se que a maioria dos pontos fracos comentados pelos grupos diz respeito ou ao modelo ou ao ambiente disponível para o trabalho, como a falta de espaço para a realização de trabalhos em grupo, o pouco tempo existente para a conclusão das tarefas e a impossibilidade de se encontrarem 
fora da sala de aula, já que é um curso noturno e a maioria trabalha durante o dia. Os pontos fortes voltam-se para a solidez do aprendizado, o resgate de conceitos já adquiridos e a maior aproximação entre o aluno e o professor permitida com a utilização do BMG na sala de aula.

Sobre a utilidade futura, foram unanimes em acreditar que utilizarão o modelo ou nas empresas em que trabalham ou na estruturação de um novo negócio. O Grupo 5 comentou que poderá utilizar o BMG para tomar decisões no futuro, o Grupo $3 \mathrm{em}$ projetos inovadores dentro das empresas e os demais grupos para empreender uma ideia no futuro.

No tocante às observações dos professores e monitores da disciplina, a dinâmica de elaboração do modelo revelou-se como uma metodologia de ensino para empreendedorismo com vistas à geração de ideias, revisão de conceitos aprendidos na administração, convergência de opiniões e, sobretudo, como uma metodologia mobilizadora dos discentes. Uma vez que a ferramenta mostrou-se como prática e relevante para os interesses pessoais e profissionais dos alunos, a mobilização dos grupos ocorreu de forma natural e determinada ao atingimento do resultado ótimo por cada grupo.

A facilidade de visualização da construção das várias etapas, de forma ordenada no decorrer do processo, permitiu aos alunos uma visão sistêmica dos conceitos administrativos, mercadológicos e financeiros envolvidos na elaboração de um modelo de negócios integrado. Outro aspecto notado que pode ter contribuído para o interesse pelo modelo por parte dos alunos foi a possibilidade de se concretizar uma proposta ou ideia de negócio que existia apenas como desejo pessoal de alguns discentes.

A forma pela qual o processo foi conduzido, mediante explanação inicial por um dos professores sobre os conceitos de cada um dos nove segmentos que compõe o BMG, bem como uma pesquisa complementar ao livro de Osterwalder e Pigneur (2010) sobre outras fontes relacionadas ao mesmo segmento, permitiu o aprofundamento do entendimento pelos alunos e possibilitou uma análise mais acurada sobre os pontos principais que compõe cada bloco do canvas. Além disso, por não se mostrar uma metodologia estática, o modelo foi passível de revisão e complementos no decorrer do processo, fato este que contribuiu para a aplicação do pensamento integrado sobre o negócio em desenvolvimento.

Outro fato relevante foi a implementação do processo de tomada de decisão pelos alunos. Eles reconheceram os problemas e dificuldades a serem superados em cada aula e puderam levantar, organizar e julgar as alternativas para a melhor escolha para os tópicos apresentados.

Um dos docentes entrevistados comentou que "devemos trazer para a sala de aula uma condição que traduza os conceitos teóricos em condições práticas acessíveis aos nossos alunos e que estes percebam a real utilidade destes conceitos no dia a dia de quaisquer empresas". Acrescentou a

Revista de Administração e Inovação, São Paulo, v. 12, n.1, p.07-23, jan./mar. 2015. 
importância do pensamento estratégico instigado nos alunos durante a utilização do BMG através da percepção da importância de se elaborar um modelo de negócios para uma empresa nascente, de forma a atender aos seus pressupostos estratégicos.

Houve um consenso entre os docentes sobre a utilização do BMG nas próximas turmas de empreendedorismo, sendo que algumas adaptações serão feitas, principalmente em função do espaço disponível para a atividade. A nova proposta considera também a possibilidade de trabalhar com um projeto único, de forma a integrar todos os alunos com um objetivo comum.

Foi especialmente interessante a aplicação do BMG em uma aula de empreendedorismo, onde muitos discentes possuem o foco na abertura de um negócio futuro. Considerando a alta taxa de mortalidade de pequenas empresas existentes no Brasil, o modelo de negócios pode ser uma boa alternativa para os novos empreendedores.

\section{CONSIDERAÇÕES FINAIS}

O presente estudo procurou descrever como utilizar o Business Model Generation em aulas de empreendedorismo, objetivando apresentar a metodologia utilizada para aplicar o modelo em sala de aula e a percepção dos alunos sobre o uso de um modelo prático durante o aprendizado.

Tratou-se de uma inciativa inovadora na disciplina que até o momento tinha como principal objetivo trazer aos alunos a experiência de empreendedores do mercado de trabalho. A utilização do modelo BMG parece ter estimulado os alunos em sala de aula, ao interagir em grupos e criar o modelo voltado a uma ideia real e aplicado a um negócio futuro. Pôde-se observar a boa receptividade de tal iniciativa e a interessante possibilidade dos alunos em desenvolver o negócio como um todo, de forma integrada.

Interessante comentar que durante a escolha dos negócios, um tema recorrente entre os alunos foi a preocupação com empresas que prezassem pelo meio ambiente e pela saúde dos consumidores. Talvez este fato esteja relacionado a uma geração mais jovem e consciente sobre a importância da gestão ambiental.

Foram citados pontos fortes e fracos da utilização do modelo, sendo que para uma próxima disciplina alguns dos pontos fracos estão sendo discutidos para aprimoramento da aplicação. Alguns aspectos foram especialmente observados pelos docentes nas aulas destinadas à utilização do BMG, destacando-se:

- A real possibilidade de inovação;

Revista de Administração e Inovação, São Paulo, v. 12, n.1, p.07-23, jan./mar. 2015. 
- A utilização de muitos conceitos aprendidos pelos alunos durante todo o curso de graduação, além da discussão de temas atuais como a co-criação;

- entusiasmo dos alunos em construir o modelo com um pensamento real de implementação futura;

- A liderança de alguns alunos no momento de apresentar os seus projetos e no momento de defender as ideias do grupo, gerando um sentimento positivo de aprendizado e discussão;

- A vontade de se organizarem e de trabalharem em equipe, sendo que alguns alunos que inicialmente se mostraram desinteressados foram cativados durante o processo;

- A apresentação dos projetos possibilitou o desenvolvimento de habilidades importantes para alunos do último período da graduação.

Sem dúvida, a aplicação do BMG revelou-se uma ferramenta pertinente e aplicável ao curso de empreendedorismo, com o objetivo de não apenas se estruturar um novo negócio, mas também como forma de se repensar um negócio já existente, incentivando o comportamento empreendedor dos discentes.

Trata-se de um estudo descritivo, qualitativo, e, portanto, os resultados apresentados referem-se ao contexto da aplicação. Além disso, os questionários foram distribuídos pelos docentes da disciplina, o que pode ter causado algum tipo de constrangimento nos discentes ao respondê-lo. Deve-se também ressaltar que as respostas referem-se a um grupo, não sendo a opinião individual dos alunos. Como sugestão futura sugere-se a utilização do modelo em outras disciplinas que não a de empreendedorismo, de forma a comparar os achados.

Acredita-se que a contribuição desse relato poderá auxiliar outros professores de graduação na decisão de utilizar o BMG em sala de aula, além de promover o início de pesquisas de temas relacionados ao modelo, uma vez que ainda são poucos os esforços acadêmicos realizados nesse sentido. 


\section{REFERÊNCIAS}

BARNEY, J. Firm Resources and Sustained Competitive Advantage. Journal of Management, 17, p. 99-120. 1991.

FLICK, U. Introdução à pesquisa qualitativa. Porto Alegre: Artmed, 2009.

FRITSCHER, B; PIGNEUR, Y. Supporting business model modelling: A compromise between creativity and constraints. Lecture Notes in Computer Science, 5963, Springer-Verlag: 28-43, 2010.

HSU, Y. Engaging students' learning process in business management: A case study of activity-based teaching. African Journal of Business Management,Vol. 5(25), pp. 10271-10275, 21 October, 2011

KIM, W. C.; MAUBORGNE, R. Blue ocean strategy: How to create uncontested market space and make the competition irrelevant. HBS Press, 2005.

KORTHAGEN, F. A. J. Linking practice and theory: the pedagogy of realistic teacher education. Annual Meeting of the American Educational Research Association, Seattle, April, 2001.

MAGRETTA, J. Why Business Models Matter. Harvard Business Review, 80(5): 86-92, 2002.

NONO, M. A.; MIZUKAMI, M. G. N. Casos de ensino e processos de aprendizagem profissional docente. Revista brasileira estudos pedagógicos, Brasília, v. 83, n. 203/204/205, p. 72-84, jan./dez. 2002.

OLIVEIRA, M.A.; FERREIRA, J. J. P. Book Review of Business Model Generation: A handbook for visionaries, game changers and challengers. African Journal of Business Management Vol.5 (7), 4 April, 2011

OSTERWALDER, A. The business model ontology: A proposition in a design science approach. $\mathrm{PhD}$ thesis. 2004. Universite de Lausanne - Ecole des Hautes Etudes Commerciales. Disponível em: http://www.hec.unil.ch/aosterwa/PhD/Osterwalder_PhD_BM_Ontology.pdf

Acesso em: 05/05/2012

OSTERWALDER, A.; PIGNEUR, Y. Business Model Generation. New Jersey: Wiley, 2010.

OSTERWALDER, A; PIGNEUR, Y; TUCCI, C.L. Clarifying business models: Origins, present, and future of the concept. Communications of the Association for Information Systems (AIS), 15, 2005.

SARASVATHY, S. D. Causation and Effectuation: Toward a theoretical shift from economic inevitability to entrepreneurial contingency. Academy of Management Review, 26(2): 243-288, 2001.

TIMMERS, P. Business Models for Electronic Markets. Journal on Electronic Markets 8(2): 3-8, 1998.

WARHURST, R. Managers' practice and managers' learning as identity formation: Reassessing the MBA contribution. Management Learning, 42(3) 261-278, 2011.

Revista de Administração e Inovação, São Paulo, v. 12, n.1, p.07-23, jan./mar. 2015. 


\begin{abstract}
The present study sought to describe how to use the Business Model Generation in entrepreneurship classes, aiming to present the methodology used to apply the model in the classroom and students' perceptions about the use of a practical model for learning. A review of the literature was about the model itself and its background and then described in the application of the Business Model Generation in the discipline of entrepreneurship at the Faculdade de Economia e Administração, Universidade de São Paulo. Qualitative interviews were conducted with groups of students, in the total of fourteen, verifying that they approved the initiative and highlighted the strengths and weaknesses of the application of the model in the classroom. In addition, was presented the perception of teachers on the use of the model. This is a descriptive, qualitative study, considered as a teaching case. It may contribute to undergraduate teaching in the decision to use the model in a classroom, and promote the initiation of research on issues related to the model, since there are few academic efforts made in this direction.
\end{abstract}

Key-Words: Business Model Generation; Entrepreneurship; Teaching case.

Data do recebimento do artigo: 05/12/2013

Data do aceite de publicação: 20/11/2014

Revista de Administração e Inovação, São Paulo, v. 12, n.1, p.07-23, jan./mar. 2015. 